\title{
Acute respiratory distress syndrome associated with tumour lysis syndrome in leukemia
}

\author{
CHAIM M BELL MD, THOMAS E STEWART MD FRCPC \\ Department of Medicine and Division of Respirology, University of Toronto, and \\ Intensive Care Unit, Wellesley-Central Hospital, University of Toronto, Toronto, Ontario
}

CM BELL, TE STEWART. Acute respiratory distress syndrome associated with tumour lysis syndrome in leukemia. Can Respir J 1997;4(1):48-51.

Acute tumour lysis syndrome (ATLS) developed in two patients with acute myelogenous leukemia soon after they were treated with cytosine arabinoside. The patients also developed respiratory distress requiring intubation. Autopsy and clinical findings demonstrated the presence of acute respiratory distress syndrome (ARDS). An association appears to be present between ARDS and ATLS in this group of patients.
Key Words: Acute respiratory distress syndrome, Acute tumour lysis syndrome, Chemotherapy, Respiratory distress

Syndrome de détresse respiratoire aiguë associé au syndrome de lyse tumorale dans la leucémie RÉSUMÉ : Deux patients atteints de leucémie myélogène aiguë ont rapidement développé un syndrome de lyse tumorale aiguë (SLTA) à la suite d'un traitement à la cytosine arabinoside. Ils ont également développé une détresse respiratoire nécessitant une intubation. L'autopsie et les résultats cliniques ont démontré la présence d'un syndrome de détresse respiratoire aiguë (SDRA). Un lien pourrait exister entre le SDRA et le SLTA dans ce groupe de patients.
$\mathrm{T}$ he treatment of acute leukemia and lymphoma may lead to acute tumour lysis syndrome (ATLS). ATLS occurs secondary to the production of tumour cell breakdown products that overwhelm the body's normal homeostatic mechanism (1). ATLS is most commonly associated with Burkitt's lymphoma $(2,3)$ but also occurs not infrequently with other high grade non-Hodgkin's lymphomas and acute leukemias. Abnormalities associated with this entity include hyperkalemia, hyperuricemia, hypocalcemia, hyperphosphatemia and azotemia. These may lead to life-threatening metabolic and electrolyte abnormalities and even death. Occasionally it has been reported that ATLS may lead to respiratory failure $(4,5)$.

Pulmonary complications of acute leukemia are numer- ous (6). They may be attributable to infection, primary leukemic infiltration, pulmonary hemorrhage or embolism and even to complications associated with therapy, occasionally including acute respiratory distress syndrome (ARDS) (6).

ARDS is a common cause of respiratory failure in critically ill patients, and has a generally accepted mortality of $50 \%$ to $70 \%(7)$. It is associated with noncardiogenic pulmonary edema, reduced lung compliance, profound hypoxemia and the need for mechanical ventilation (8). Although ARDS is not a common pulmonary complication of acute leukemia, it has been reported in the absence of infection $(4,6,9,10)$. Two cases of patients with acute leukemia who developed ARDS associated with ATLS are described.

Correspondence and reprints: Dr TE Stewart, Wellesley-Central Hospital, 160 Wellesley Street East, Suite 245, Jones Building, Toronto, Ontario M4Y 1J3. Telephone 416-926-7962, fax 416-926-5140, e-mail tom.stewart@utoronto.ca 
TABLE 1

Selected laboratory values (case 1)

\begin{tabular}{lccc}
\hline Time $(\mathbf{h})$ & $\begin{array}{c}\text { White blood cell } \\
\text { count }(\times \mathbf{1 0})\end{array}$ & $\begin{array}{c}\text { Potassium } \\
(\mathbf{m m o l} / \mathbf{L})\end{array}$ & $\begin{array}{c}\text { Phosphate } \\
(\mathbf{m m o l} / \mathbf{L})\end{array}$ \\
\hline $0^{*}$ & 151 & 1.7 & 0.13 \\
10 & 121.5 & 2.3 & $\mathrm{~N} / \mathrm{a}$ \\
14 & 131.5 & 8.9 & $\mathrm{~N} / \mathrm{a}$ \\
24 & 100.5 & 3 & 0.5 \\
48 & 55 & 7.5 & 3.46 \\
\hline
\end{tabular}

*Time when chemotherapy initiated. N/a Data unavailable

TABLE 2

Selected laboratory values (case 2)

\begin{tabular}{lccc}
\hline Time (h) & $\begin{array}{c}\text { White blood cell } \\
\text { count }\left(\mathbf{\times 1 0 ^ { 9 }} / \mathbf{L}\right)\end{array}$ & $\begin{array}{c}\text { Potassium } \\
\text { ( } \mathbf{m m o l} / \mathbf{L})\end{array}$ & $\begin{array}{c}\text { Phosphate } \\
(\mathbf{m m o l} / \mathbf{L})\end{array}$ \\
\hline $0^{*}$ & 198 & 2.2 & 0.57 \\
10 & 139 & 3.9 & $\mathrm{~N} / \mathrm{a}$ \\
20 & 115 & 2.5 & 0.73 \\
24 & $\mathrm{~N} / \mathrm{a}$ & 6.9 & 1.98 \\
26 & $\mathrm{~N} / \mathrm{a}$ & 7.3 & 2.1 \\
32 & $\mathrm{~N} / \mathrm{a}$ & 7.5 & 2.49 \\
48 & 11.4 & 7.1 & $\mathrm{~N} / \mathrm{a}$ \\
\hline
\end{tabular}

*Time when chemotherapy initiated. N/a Data unavailable

\section{CASE PRESENTATIONS - CASE 1}

A 74-year-old previously healthy woman presented with a one-month history of fever, chills and malaise. On physical examination, there were subconjunctival and mucosal petechiae and hepatosplenomegaly. A complete blood count demonstrated hemoglobin of $74 \mathrm{~g} / \mathrm{L}$, white blood cell count (WBC) of $151 \times 10^{9} / \mathrm{L}$ (Table 1 ) with $110 \times 10^{9} / \mathrm{L}$ blasts and $109 \times 10^{9} /$ L platelets. Her bone marrow biopsy was consistent with acute myelogenous leukemia (AML $\mathrm{M}_{4}$ ). Chest x-ray was normal.

The patient was treated with leukophoresis, aggressive hydration, alkalinization of her urine, allopurinol and hydroxyurea. Induction chemotherapy was begun with cytosine arabinoside $320 \mathrm{mg} /$ day. Within hours she became profoundly hypoxemic, requiring $100 \%$ oxygen to obtain an arterial oxygen saturation of $92 \%$. She also became febrile, oliguric and hypotensive requiring inotropes. Chest $\mathrm{x}$-ray showed diffuse bilateral patchy infiltrates with airspace consolidation (Figure 1). WBC had decreased from $155 \times 10^{9} / \mathrm{L}$ to $55 \times 10^{9} / \mathrm{L}$, and potassium and phosphate had increased to $7.5 \mathrm{mmol} / \mathrm{L}$ (normal 3.5 to 5.0 ) and $3.46 \mathrm{mmol} / \mathrm{L}$ (normal 0.85 to 1.85 ), respectively. Calcium was $2.12 \mathrm{mmol} / \mathrm{L}$ (normal 2.2 to 2.6), and lactate dehydrogenase was $1259 \mathrm{U} / \mathrm{mL}$ (normal less than 200).

The patient was transferred to the intensive care unit (ICU) with a diagnosis of tumour lysis syndrome and respiratory distress. She was intubated, and mechanical ventilation was instituted. A pulmonary artery catheter was placed and confirmed noncardiogenic pulmonary edema (pulmonary artery occlusion pressure $8 \mathrm{mmHg}$ ).

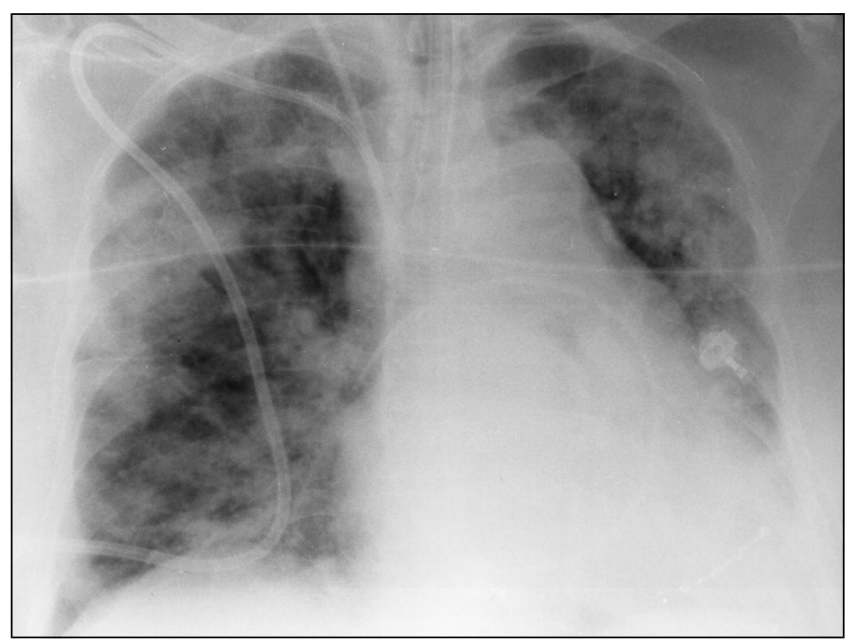

Figure 1) Case 1 chest $x$-ray showing diffuse bilateral patchy infiltrates with airspace consolidation which, along with other clinical and hemodynamic parameters, is consistent with acute respiratory distress syndrome

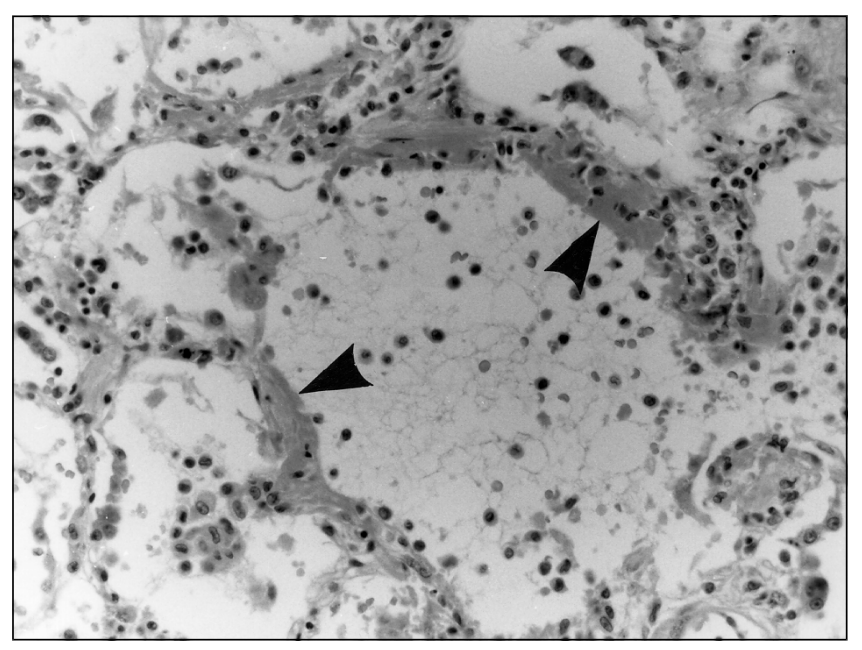

Figure 2) Case 1 autopsy lung findings. Film demonstrates diffuse alveolar damage with hyaline membrane formation (black arrows) consistent with acute respiratory distress syndrome. A mononuclear and neutrophilic inflammatory cell infiltrate is seen in the alveolar space and within the interstitium (hematoxylin and eosin stain, magnification $400 \times$ )

The patient developed acute renal failure secondary to tumour lysis syndrome, and hemodialysis was initiated. Bronchoscopy was performed to rule out infections and pulmonary hemorrhage. Her blood, urine, sputum, cytomegalovirus and acid-fast baccillus cultures were negative and remained negative throughout her ICU stay.

Despite aggressive care, the patient died. Autopsy confirmed ARDS with no evidence of bronchopneumonia. There was $200 \mathrm{~mL}$ of blood-tinged pleural fluid in each lung. Lung sections showed pulmonary congestion, edema and recent hemorrhage with diffuse hyaline membranes. The alveolar capillaries, lymphatics and perilymphatic soft tissues were infiltrated with blasts (Figure 2). 


\section{CASE 2}

A 53-year-old man presented with headaches, fever, chills, petechiae on his legs and bloody diarrhea. Physical examination revealed a temperature of $39.1^{\circ} \mathrm{C}$, bilateral cervical lymphadenopathy and oral mucosal hemorrhage. His hemoglobin was $87 \mathrm{~g} / \mathrm{L}$, WBC $198 \times 10^{9} / \mathrm{L}$ (Table 2) with $147 \times 10^{9} / \mathrm{L}$ blasts and platelet count of $29 \times 10^{9} / \mathrm{L}$. He was leukophoresed, aggressively hydrated and given hydroxyurea and allopurinol. Bone marrow biopsy showed acute leukemia (AML M4).

Treatment with cytosine arabinoside and daunorubicin was started. He then developed shortness of breath and diminished urine output. Biochemistry tests showed potassium of $7.3 \mathrm{mmol} / \mathrm{L}$ (normal 3.5 to 5.0 ), creatinine of $252 \mu \mathrm{mol} / \mathrm{L}$ (normal 60 to 100), lactate dehydrogenase $14530 \mathrm{U} / \mathrm{mL}$ (normal less than 200), calcium $1.73 \mathrm{mmol} / \mathrm{L}$ (normal 2.2 to 2.6 ), uric acid $5111 \mu \mathrm{mol} / \mathrm{L}$ (normal 120 to 420 ) and phosphate $2.10 \mathrm{mmol} / \mathrm{L}$ (normal 0.85 to 1.85 ). Chest $\mathrm{x}$-ray showed atelectasis at the right lung base, an elevated right hemidiaphragm and perihilar airspace consolidation. Blood cultures grew a Gram-positive bacillus (shown later to be Listeria monocytogenes), and he was started on ampicillin and gentamicin. Thus, there was a preliminary diagnosis of sepsis and acute renal failure secondary to ATLS. His oxygenation deteriorated, and he required intubation, ventilation and transfer to the ICU. A pulmonary artery catheter was placed and confirmed noncardiogenic pulmonary edema (pulmonary artery occlusion pressure $13 \mathrm{mmHg}$ ).

Bronchoscopy demonstrated no active bleeding or infection (including cytomegalovirus, Pneumocystis carinii, herpes simplex virus and varicella zoster virus). Hemodialysis was initiated. Despite aggressive care, two weeks after admission to the ICU he died. Autopsy findings were consistent with ARDS, and no signs of infection were detected.

\section{DISCUSSION}

We have presented two cases of ARDS in association with ATLS in patients commencing chemotherapy for acute leukemia (AML M4). ARDS was confirmed in both patients by noncardiogenic pulmonary edema, profound hypoxemia and need for mechanical ventilation. Both patients succumbed to their disease, and autopsy confirmed the diagnosis of ARDS.

Pulmonary complications, especially infiltrates, in a leukemic population are common and pose a diagnostic challenge. In one series of 139 leukemic patients, $82 \%$ of localized pulmonary infiltrates were related to an infectious etiology while none were related to the leukemic process (11). In contrast, diffuse lung infiltrates had an infectious cause $35 \%$ of the time while $20 \%$ of the time they were attributable to the leukemic process (11). ARDS is frequently reported in immunocompromised patients but infrequently reported as a complication of acute leukemia $(4,6,9,10,12,13)$.

Obstruction of the pulmonary microvessels, including capillaries, by tumour growth leading to endothelial and alveolar cell injury has been implicated as a potential mechanism of ARDS in leukemic patients $(4,12)$. This is supported by the finding of pulmonary leukostasis at autopsy in more than $10 \%$ of patients dying of acute leukemia (especially when WBC counts are over $\left.100 \times 10^{9} / \mathrm{L}\right)(14)$. As well, the release of vasoactive cell breakdown products and inflammatory mediators by the dying tumour cells and during reperfusion has been implicated as a cause of endothelial and alveolar damage leading to respiratory failure (4).

Cytosine arabinoside has even been implicated in precipitating episodes of ARDS, perhaps through intrapulmonary cell lysis (15) or direct injury to endothelial surfaces (13). One series showed that 13 of 103 patients with acute or chronic leukemia in blast phase who were treated with cytosine arabinoside developed ARDS (10). The finding of acute tumour lysis syndrome may be an indicator of elevated WBC count, ie, increased tumour burden. High tumour burden would be especially deleterious in the pulmonary vasculature, thus predisposing to pneumopathy. Therefore, the chemotherapeutic agent may play an important role in initiating the process, as this entity has also been described with another antimetabolite, fludarabine (5).

Our patients presented with respiratory distress and tumour lysis syndrome shortly after initiating chemotherapy to treat the acute leukemia, even with preventative measures towards ATLS. The clinical data, laboratory results and autopsy findings confirm the presence of ARDS. The damage causing the ARDS may have occurred through a variety of mechanisms, but almost certainly the chain of events was initiated by the commencement of chemotherapy. Clinicians treating patients with leukemia should be aware of this potential life-threatening complication.

ACKNOWLEDGEMENT: We thank Dr DM Battaglia, Department of Pathology, Wellesley-Central Hospital, Toronto, Ontario, for her help with the pathology specimens and their interpretation.

\section{REFERENCES}

1. Warrel RP, Bockman RS. Metabolic emergencies. In: DeVita VT, Hellman S, Rosenberg SA, eds. Cancer: Principles and Practice of Oncology. Philadelphia: JB Lippincott, 1989:1986-2002.

2. Cohen LF, Balow JE, Magrath IT, Poplack DG, Ziegler JL. Acute tumour lysis syndrome. Review of 37 patients with Burkitt's lymphoma. Am J Med 1980;68:486-91.

3. Tsokos GC, Balow JE, Spiegel RJ, MaGrath IT. Renal and metabolic complications of undifferentiated and lymphoblastic lymphomas. Medicine (Baltimore) 1981;60:218-29.

4. Dombret H, Hunault M, Faucher C, Dombret M-C, Degos L. Acute lysis pneumopathy after chemotherapy for acute myelomonocytic leukemia with abnormal marrow eosinophils. Cancer 1992;69:1356-61.

5. Crowley JJ, Knight L, Charan N. Lysis pneumopathy associated with the use of fludarabine phosphate. West J Med 1994;161:597-9.

6. Hewlett RI, Wilson AF. Adult respiratory distress syndrome following aggressive management of extensive acute lymphoblastic leukemia. Cancer 1977;39:2422-5.

7. Montgomery AB, Stager MA, Carrico CJ, Hudson LD. Causes of mortality in patients with the adult respiratory distress syndrome. Am Rev Respir Dis 1985;132:485-9.

8. Murray JF, Matthay MA, Luce JM, Flick MR. An expanded definition of the adult respiratory distress syndrome. Am Rev Respir Dis 1988;138:720-3.

9. Pentimone F, Cini G, Ferrannini E. Acute respiratory distress syndrome in an adult patient with a myelodysplastic disorder. Acta Haematol 1983;69:208-11.

10. Andersson BS, Luna MA, Yee C, Hui KK, Keating MJ, McCredie KB. Fatal pulmonary failure complicating high dose cytosine arabinoside therapy in acute leukemia. Cancer 1990;65:1079-84. 
11. Tenholder MF, Hooper RG. Pulmonary infiltrates in leukemia. Chest 1980;78:468-73.

12. Myers TJ, Cole SR, Klatsky AU, Hild DH. Respiratory failure due to pulmonary leukostasis following chemotherapy of acute nonlymphocytic leukemia. Cancer 1983;51:1808-13

13. Vansteenkiste JF, Boogaerts MA. Adult respiratory distress syndrome in neutropenic leukemia patients. Blutalkohol 1989;58:287-90.

14. Bodey GP, Powell RD, Hersh EM, Yeterian A, Freidrich EJ. Pulmonary complications of acute leukemia. Cancer 1966;19:781-93.

15. Haupt HM, Hutchins GM, Moore GW. Ara-C lung: Noncardiogenic pulmonary edema complicating cytosine arabinoside therapy of leukemia. Am J Med 1981;70:256-61.

\section{BOOKS}

Respiratory Physiology: People and Ideas, edited by John B West (1996). American Physiological Society. Oxford University Press, 70 Wynford Drive, Don Mills, Ontario M3C 1J9. 431 pages; ISBN 0-1950-8081-5; $\$ 121.95$.

This book is the latest in the American Physiology Society series "People and Ideas", which began in 1982 with Circulation followed by Renal Physiology, Endocrinology and Membrane Transport. The aim, succinctly summarized by the title, is to provide an account of the personalities who developed modern concepts of physiology. While some chapters do begin with Boyle and Lavoisier, most focus on how ideas evolved and, in a broader sense, how physiological research has been conducted from 1940 to the present day. The success of such an account obviously depends in part on first-hand accounts by those who were involved. The names of the contributors ensure success on this count: Weibel, Astrup, Severinghaus, Clements, Forster, Mead, Staub, von Euler, West, among others. They constitute a Who's Who of the leaders in the field of that time. They provide accounts that are uniformly of high quality and entirely suitable as an introduction to respiratory physiology for the budding researcher. However, what the reader gets is much more than this: the excitement of research, the interactions between people from different backgrounds, the discussions and the times when the light suddenly suddenly switches on are all vividly presented, particularly in the chapters by Jere Mead ("Mechanics of lung and chest wall"), Bob Forster ("Transfer of gas by diffusion and chemical reaction pulmonary capillaries") and John Clements ("Lung surface tension and surfactant"). Several of the contributors have taken the opportunity to revisit controversies, explain the issues and outline how they were resolved. Mistakes are admitted, and in some cases history is rightly rewritten. Shining through the book is the charisma of these leaders, charisma that allowed them to act effectively as mentors and colleagues; the degree of collaboration between individuals and groups seems to have been one reason for the momentum of research during this time. In short, this is as close to being impossible to put down as any scientific book I have seen, combining the flavours of Physiological Reviews with more popular books such as The Double Helix.

There are some disappointments; one or two chapters are straightforward reviews, excellent in their way but lack a personal touch. There is some repetition - you can read three accounts of the oxygen secretion controversy - and some chapters end disappointingly early (Norman Staub's in 1967, for example). Strangely, John West's own chapter on gas exchange misses the opportunity to detail the marvels of the $\mathrm{O}_{2}: \mathrm{CO}_{2}$ diagram and contains no description of his own experimental work in the 1960s at the Postgraduate Medical School in London. Several names I expected to see, are missing, but there is bound to be some variation in perspective, depending on where one was and what one was doing. Finally, while the neurophysiology of breathing control is covered in fine detail, human studies in this field do not feature prominently. These are minor criticisms that may not be shared by others with different interests.

A feature of the book is the extensive bibliography provided with each chapter; the many photographs and reproductions from ground-breaking papers enhance the text, and the production is up to the publishers usual high standards. However, the book's high cost may prompt its acquisition by libraries rather than individuals which is a shame. At the very least it should be given to research fellows on their first day in the lab!

Norman Jones MD McMaster University Hamilton, Ontario 


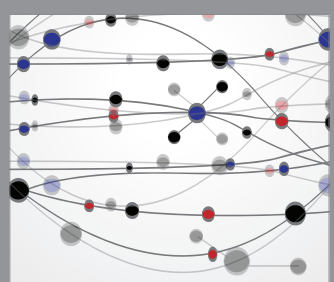

The Scientific World Journal
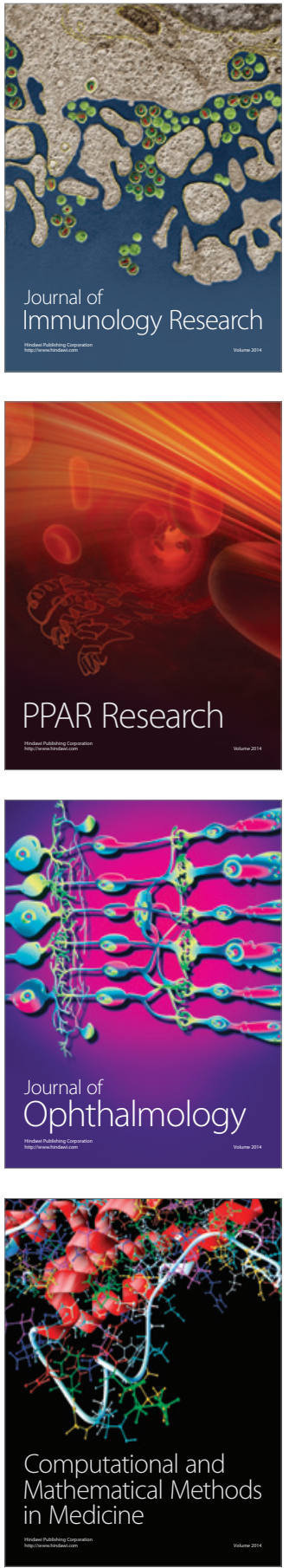

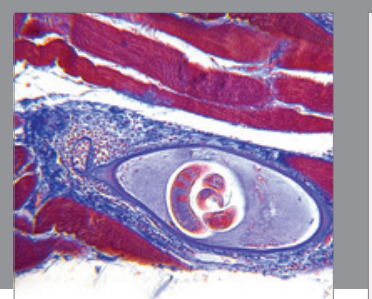

Gastroenterology Research and Practice

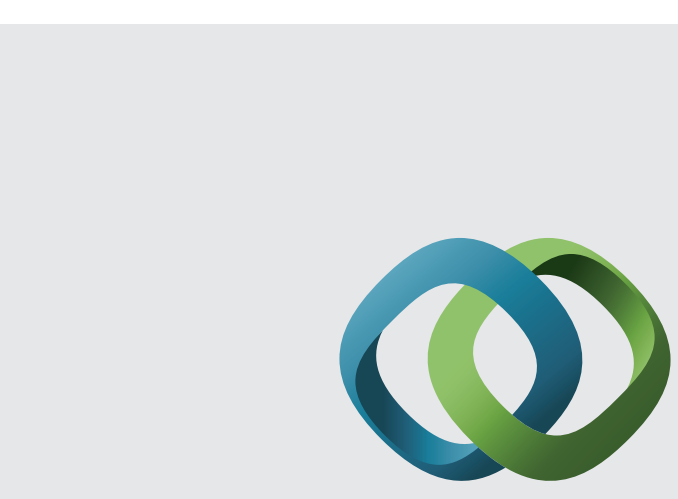

\section{Hindawi}

Submit your manuscripts at

http://www.hindawi.com
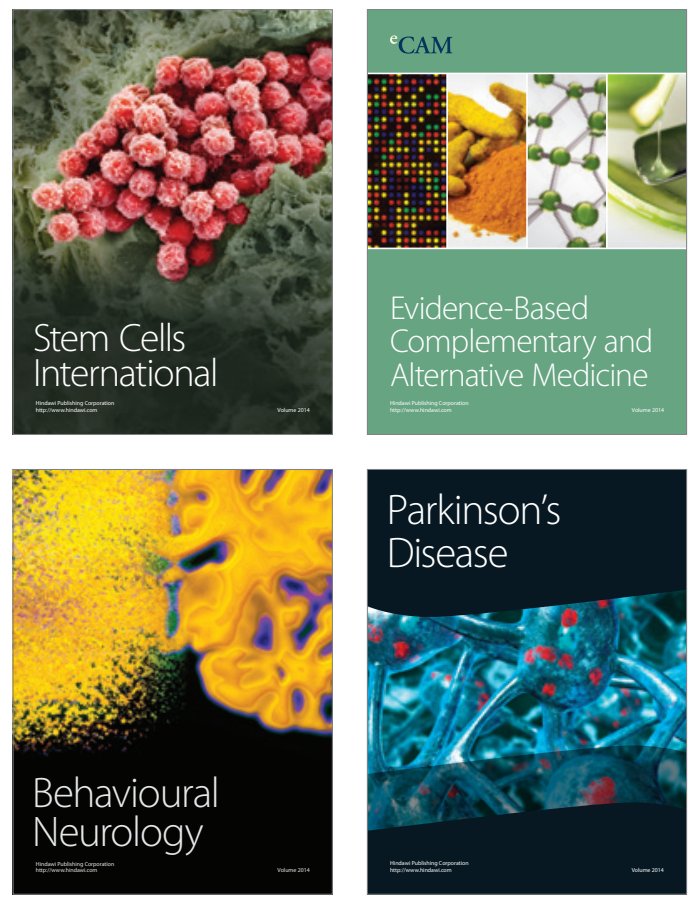
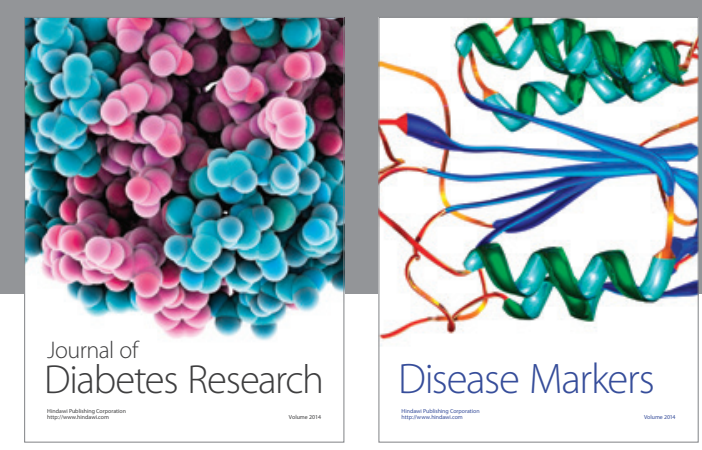

Disease Markers
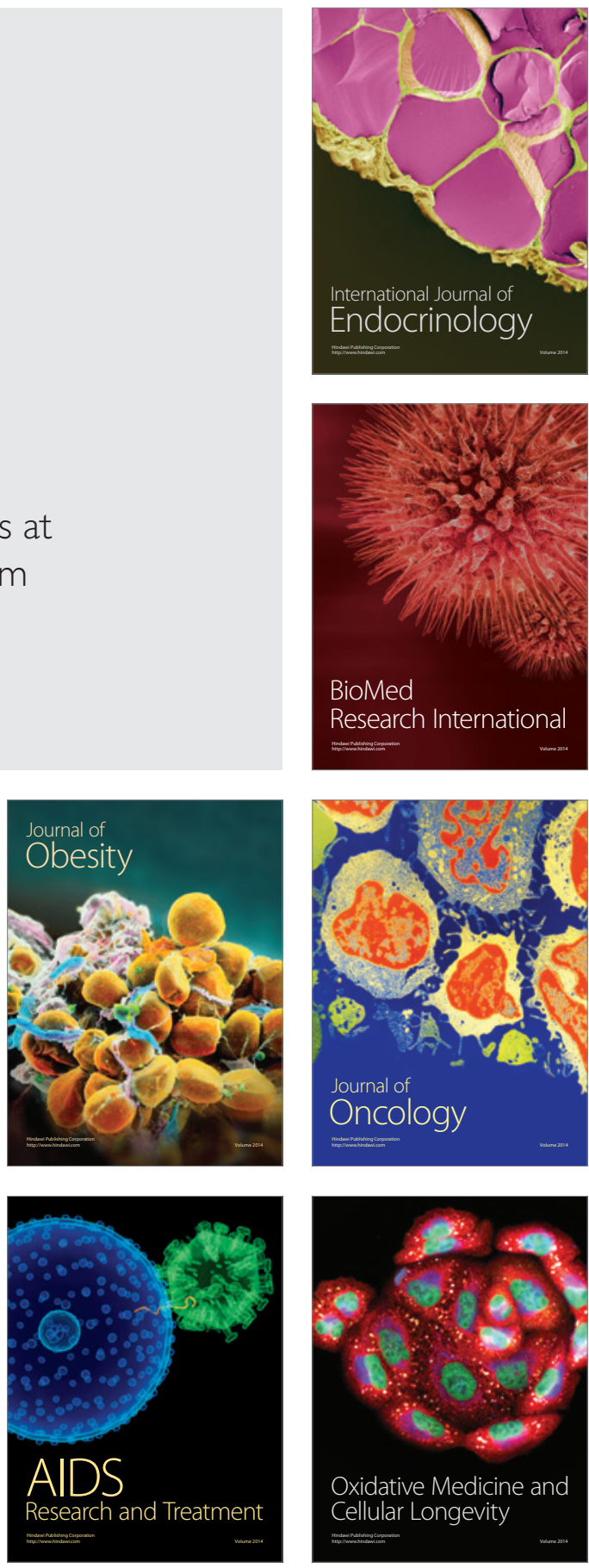